\title{
Evolution to a Renowned International Journal
}

Jeong Tae Kim, MD

Editor-in-Chief, Archives of Plastic Surgery

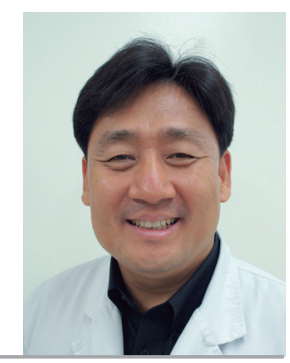

Since 1974 when the Journal of the Korean Society of Plastic and Reconstructive Surgeons was first published, 179 issues have been published. Considering that the Korean Society of Plastic and Reconstructive Surgeons (KSPRS) was founded in 1966, it is certain that many forerunners in the Society made a great effort to publish the Journal in its embryonic stage. We have finally published six issues every year since 1989, having earlier initiated semi-annual publication in 1976, triannual publication in 1982, and quarterly publication in 1983. I want to express appreciation for the ongoing effort of many editors-in-chief who maintained a tradition of the Journal worthy of its name as a professional journal of Korean specialists in plastic and reconstructive surgery [1].

As many of you know, the last Korean language issue of the Journal of the Korean Society of Plastic and Reconstructive Surgeons was published with 31 articles in the November 2011, and the Journal has finally been transformed into an English version beginning in 2012. After vigorous discussion and debate, the Journal has been renamed Archives of Plastic Surgery (Arch Plast Surg, APS). Moreover, over the past year, we have had an ongoing effort to establish all the infrastructure and resources necessary to successfully undertake this transition to an English language journal: to run a new website, maintain an English online submission system, appoint more than 20 international reviewers, secure more than 80 internal reviewers, and invite 10 review article contributors. Our journal now meets you with its new cover design and contents. Though there had already been increasing submission of English language articles to the original Korean Journal, our new English language Journal evidences the willingness of our academic society's progressive attitude toward pursuing globalization and keeping up with medical tourism, a task national in scope. I am eager for this English journal to bring good news to many members who generously participate in overseas volunteer work and plastic treatment, and to the Korean plastic surgeons who give lectures or presentations abroad. Also I earnestly want Archives of Plastic Surgery to build connections among plastic surgeons of various countries, including Asian countries other than Korea, to share information, and to encourage academic interaction.

Archives of Plastic Surgery is intended to bring in the participation of more readers through monthly publication despite present principle of six publications a year with three peer reviews. This will open the door for article submission not only to those in Asian countries but also to plastic surgeons worldwide. Academically, Archives of Plastic Surgery will deal with subjects of all areas of cosmetic and reconstructive surgery, including basic science and experimental trials. APS, with its emphasis on the immediacy of thesis publication, seeks to peer-review on its principle of twoweek evaluation and seeks to minimize the time gap of delivery of knowledge between authors and readers by rapidly determining whether to accept or reject. We are planning to mainly focus on Original Articles in Archives of Plastic Surgery and Case Reports will provide beneficial information to readers together with the newly-established category of Image. Furthermore, we intend to build close ties among readers by providing readers with useful information through the newly-organized sections of Communications or Book Reviews and intend to provide additional guidance to readers with announcements of international meetings. Our regulations for thesis submission were revised in October, 2011, to provide detailed information for contributors, and we especially hope that APS can provide a place for active debates

Copyright $(\odot 2012$ The Korean Society of Plastic and Reconstructive Surgeons

This is an Open Access article distributed under the terms of the Creative Commons Attribution Non-Commercial License (http://creativecommons.org/

licenses/by-nc/3.0/) which permits unrestricted non-commercial use, distribution, and reproduction in any medium, provided the original work is properly cited.

www.e-aps.org 
and communication among plastic surgeons worldwide by encouraging their article submissions. We want authors to become thoroughly familiar with these submission regulations to avoid any disadvantage or delay in publication [2].

As an Editor-in-Chief, I would especially like to emphasize the ethical dimension of paper submission and the matter of patient consent. Because readers worldwide can now read the articles of APS with the conversion to an international journal, contributors need to take special care about research ethics, including overlapping publication or plagiarism. Now with this new first step of APS into international publication, content in locally-published academic journal articles overlapping with foreign journal articles will become painfully obvious and should be eradicated. With APS's publication of an English version of its journal, we are declaring a definite turning point in enforcing these ethical standards more rigorously by using CrossCheck or other tools that can search for duplications in content between a submitted article and articles already published around the world. Moreover, given the distinctiveness of plastic surgery, in that photos and videos contributed in a paper require patient agreement, an author should refer to the patient consent form recommended by the publication committee of APS. This is a matter that we all should be specially prepared for from now on, as it aims to prevent the possibility of conflicts including portrait rights in advance.

Now Archives of Plastic Surgery has begun its intense preparation for qualification as an SCI(E) journal and listing in all sorts of indices such as PubMed Central. Soon, through expansion to an e-journal, we will also jump into open access, making our work more accessible to many readers and reaching new readers for the first time. We are about to see the rapid sharing of new knowledge through these various mediums. Lastly, I want to offer words of thanks to the members of the editorial board, reviewers, related corporations, and the office workers of publication committee for advising and helping the Korean Society of Plastic and Reconstructive Surgeons to publish this English language journal.

\section{REFERENCES}

1. Lew JM, Kim IG. A review of the 1857 papers of Journal of the Korean Society of Plastic and Reconstructive Surgeons: in commemoration of the 30th anniversary of the founding KSPRS. J Korean Soc Plast Reconstr Surg 1997;24:11-31.

2. Uniform requirements for manuscripts submitted to biomedical journals. International Committee of Medical Journal Editors. BMJ 1991;302:338-41.

Correspondence: Jeong Tae Kim

Department of Plastic and Reconstructive Surgery, Hanyang University Medical Center, 345 Wangsimni-gil, Sungdong-gu, Seoul 133-792, Korea

Tel: +82-2-2290-8560, Fax: +82-2-2295-7671, E-mail: jtkim360@gmail.com

No potential conflict of interest relevant to this article was reported.

pISSN: 2234-6163 • elSSN: 2234-6171

http://dx.doi.org/10.5999/aps.2012.39.1.1 • Arch Plast Surg 2012;39:1-2 